\title{
Analysis of factors affecting the semen pathology in male infertility
}

\author{
Tandel H.K ${ }^{1}$, Patel Y.K. ${ }^{2}$ \\ ${ }^{1}$ Dr. Hetal Kumari Kishor Bhai Tandel, Tutor, ${ }^{2}$ Dr. Yogita Kumari Manilal Patel, Tutor, both authors are affiliated with \\ Department of Pathology, GMERS Medical College, Valsad, Gujarat, India.
}

Corresponding Author: Dr. Yogita Kumari Manilal Patel. E-mail: dr.yogita257@gmail.com

\begin{abstract}
Background: Abnormalities in the male are the sole cause of infertility in approximately $20 \%$ of infertile couple and important contributing factor in another $20-40 \%$ of couple with reproductive failure. Despite our ability to assess sperm quality through a semen analysis methodology harmonized across laboratories, the use of these parameters cannot precisely and accurately predict the fertility of a man presenting to a clinician. Objectives: to evaluate various factors for male infertility and correlate various factors which affect the semen quality. Methodology: It was a prospective observational study done over a period of two years. Semen was examined for physical appearance, viscosity, volume, $\mathrm{pH}$, sperm motility, biochemical test fructose, sperm count and the morphology for sperm was done. Results: $84 \%$ patients were presented as primary infertility and $16 \%$ presented as secondary infertility. $35 \%$ of patients had oligozoospermia, $42.5 \%$ patients had oligoazoospermia and $17 \%$ of patients had azoospermia. Only 35 out of 118 smoker had $>50 \%$ motility while 25 had motility of $<5 \%$. Also teratozoospermia dominated in alcoholics [65(32.5\%)]. 25 out of 60 obese patients had sperm motility $<5 \%$. While 10 out of 70 overweight and 5 out of 70 normal weight patients had sperm motility $<5 \%$. Conclusion: Smoking and alcohol decrease fertility by decreasing sperm count, motility and also by changing the morphology of sperm. Obesity also directly contributes in the fertility of a person by altering the hormonal status of patients.
\end{abstract}

Keywords: Semen analysis, Smoking, Alcohol, Obesity, male Infertility

\section{Introduction}

Infertility is common problem affecting nearly one out of the six couples. Among them male infertility is a problem of the reproductive system, and the word infertility itself means no fertile, and that would be equivalent to sterility [1]. Sterility means that a man is totally unable to have a child [2].

As the definition given by WHO and the American Society for Reproduction Medicine Practice Committee, infertility means no conception after at least 12 months of unprotected sexual intercourse [3]. Infertility can be permanent or subfertility which means the probability of spontaneous conception may be decreased [1]. Abnormalities in the male are the sole cause of infertility in approximately $20 \%$ of infertile couple and important contributing factor in another $20-40 \%$ of couple with reproductive failure [4]. Infertility can either be primary or secondary; primary male infertility is when the man has never impregnated a woman, while

Manuscript received: $14^{\text {th }}$ August 2017

Reviewed: $24^{\text {th }}$ August 2017

Author Corrected: $30^{\text {th }}$ August 2017

Accepted for Publication: $4^{\text {th }}$ September 2017 secondary male infertility is when a man has impregnated a woman irrespective of the outcome of the pregnancy[3]. Men with secondary infertility, in general, have better chance of future fertility [3].

Duration of infertility is defined as the number of months during which the couple has been having sexual intercourse without the use of any contraceptive method [3]. This indicator gives an important information about the couple's future fertility, if the duration of infertility of 3 years or less the couples have a better chance of future pregnancy, but if the duration has been longer, then there is a severe biological problem [1]. Despite our ability to assess sperm quality through a semen analysis methodology harmonized across laboratories, the use of these parameters cannot precisely and accurately predict the fertility of a man presenting to a clinician.

The objective of the study was to evaluate various factors for male infertility and correlate various factors which affect the semen quality. 


\section{Materials and methods}

Study design and setting: This is prospective observational study in which total 200 cases of infertility were enrolled during the period of July 2013 to November 2015 B J Medical College.

Inclusion and Exclusion criteria: All patients who came to us in outdoor patient pathology laboratory were included in the study. There were no any exclusion criteria.

Detailed clinical history inclusive of their presenting complaints, type of infertility, age of patient, occupation, education, detailed marital history, relevant family \& past history, inclusive of medical, surgical illness if any.

Past consultation, urological history \& sexual history were elicited. General physical and local examination of penis, scrotum, testis, vas deference, prostate, seminal vesicle was done. Patients were examined for neurological defects.

After explaining to patient semen was collected after 3 days of abstinence. The sample was received in laboratory within $30 \mathrm{~min}$ of collection. Entire sample were obtained by masturbation in clean wide mouth plastic container provided by laboratory. Container was labelled with patient name, registration number, time \& date of collection.

Sample was examined by physical appearance, viscosity, volume and $\mathrm{pH}$. After physical examination wet preparation for sperm motility. Biochemical test for fructose is carried out. Sperm count in percentage with the help of neubauer counter chamber and stained with field's stain to check the morphology for sperm.

Method for sperm motility:

1. Place a drop of semen on glass slide $\&$ cover with a coverslip.

2. Examine under high power(40x).

3. Count a total 100 spermatozoa, and note out of the hundred how many are motile. Record the percentage that are motile and non motile.

\section{Original Research Article}

\section{Method of Sperm count:}

1. Semen was diluted 1:20 with formalin. $(0.1 \mathrm{ml}$ semen and $1.9 \mathrm{ml}$ formalin)

2. Charge the Neubauer++ chamber with diluted semen sample.

3. Sample was allowed to settle for 10 to 15 minutes.

4. The chamber was placed under the microscope and spermatozoa were counted in 4 large corners squares using the $20 \mathrm{x}$ or $40 \mathrm{x}$ objectives

5. Sperm count per $\mathrm{ml}$ was calculated as follows:

$\frac{\text { Spermscounted }(N) x \text { correctionfactorfordilution }(20)}{\text { Noof squarescounted }(4) \text { xvolumeof } 1 \text { square }(0.1)} \times 1000$

$=\mathrm{N} \times 50000 / \mathrm{ml}$.

Smear examination for sperm morphology :

1. Place a drop of semen on a glass slide and prepared a smear.

2. Stained the smear with field stain.

3. At least 200 spermatozoa counted under oil immersion.

4. Percentage of normal \& abnormal spermatozoa recorded.

\section{Biochemical test}

Fructose test:

1. Taken 3 test tubes.

2. In 1 st test tube, take $2 \mathrm{ml}$ fructose reagent $\& 0.1 \mathrm{ml}$ distilled water as negative control.

3. In 2 nd test tube, take $2 \mathrm{ml}$ fructose reagent $\& 0.1 \mathrm{ml}$ positive control.

4. In 3rd test tube, take $2 \mathrm{ml}$ fructose reagent $\& 0.1 \mathrm{ml}$ sample.

5. Boil in hot water bath for 2 minutes, cool and compare the colour with positive and negative controls.

6. Note the reading along with positive and negative control.

\section{Results}

The study was done with collaboration with the department of Obstetrics\& Gynecology. Total 200 patients of infertility was taken into consideration over a period of 2 years. $160(80 \%)$ of patients were from urban area and $40(20 \%)$ from rural area. As seen in table 1, more than half i.e. $56 \%$ of patients were from age group of 25 - 30 years of age with ranges from 21 to 40 years of age. 


\section{Original Research Article}

Occupation wise distribution shows that majority of the patients is from middle and lower middle class who are manual worker by their occupation [Table 2 ]. As seen in table 3 , majority of the patients $(\sim 70 \%)$ have active marriage life less than 5 years.

Table-1: Age wise distribution of all infertile patients.

\begin{tabular}{|c|c|c|}
\hline Age & No of patients & Percentages \\
\hline $21-25$ & 56 & $28 \%$ \\
\hline $26-30$ & 112 & $56 \%$ \\
\hline $31-35$ & 24 & $4 \%$ \\
\hline $36-40$ & 8 & $\mathbf{1 0 0} \%$ \\
\hline
\end{tabular}

Table-2: Occupation wise distribution of all infertile patients.

\begin{tabular}{|c|c|c|}
\hline Occupation & Frequency & Percentage \\
\hline Laborers & 24 & $12 \%$ \\
\hline Factory workers & 16 & $8 \%$ \\
\hline Vendor & 16 & $8 \%$ \\
\hline Shopkeeper & 16 & $8 \%$ \\
\hline Driver & 16 & $8 \%$ \\
\hline Teacher & 16 & $48 \%$ \\
\hline Other & 96 & $\mathbf{1 0 0} \%$ \\
\hline Total & $\mathbf{2 0 0}$ & $8 \%$ \\
\hline
\end{tabular}

Type of infertility shows, $84 \%$ patients were presented as primary infertility and $16 \%$ presented as secondary infertility. Semen analysis report is seen in table 4.

Majority of patients (72\%) had semen quantity less than $2 \mathrm{cc}$ and $84 \%$ of patients had sperm density of $>20 \mathrm{million} / \mathrm{ml}$.

However actively motile sperm was seen in only $20 \%$ of patients. Sluggishly motile sperm was seen in $25 \%$ of patients and non-motile sperm were seen in $55 \%$ of patients.

Frequency of motile sperm shows that $60 \%$ of patients had $<20 \%$ motile sperm. $35 \%$ of patients had oligozoospermia, $42.5 \%$ patients had oligoazoospermia and $17 \%$ of patients had azoospermia. $>50 \%$ of patients had pus cells $>10 / \mathrm{HPF}$.

Table-3: duration of active married life.

\begin{tabular}{|c|c|c|}
\hline Duration of active married life in years & No of patients & Percentages \\
\hline $2-3$ & 72 & 36 \\
\hline $3.1-5$ & 64 & 20 \\
\hline $5.1-7$ & 40 & 4 \\
\hline $7.1-9$ & 16 & $\mathbf{1 0 0}$ \\
\hline $9.1-15$ & 8 & $\mathbf{2 0 0}$ \\
\hline Total & & \\
\hline
\end{tabular}




\section{Original Research Article}

Table-4: Semen analysis parameters.

\begin{tabular}{|c|c|c|}
\hline Semen analysis & No. of patients & Percentages \\
\hline \multicolumn{3}{|c|}{ 1. Quantity (c.c.) } \\
\hline$<1$ & 32 & 16 \\
\hline $1.1-2$ & 114 & 57 \\
\hline $2.2-3$ & 32 & 16 \\
\hline$>3$ & 24 & 12 \\
\hline Total & 200 & 100 \\
\hline \multicolumn{3}{|c|}{ 2. Sperm density (million/ml) } \\
\hline$>20$ & 168 & 84 \\
\hline $10.1-20$ & 24 & 12 \\
\hline$<10$ & 8 & 4 \\
\hline Total & 200 & 100 \\
\hline \multicolumn{3}{|c|}{ 3. Sperm motility } \\
\hline Actively motile & 40 & 20 \\
\hline Sluggishly motile & 50 & 25 \\
\hline Non-motile & 110 & 55 \\
\hline \multicolumn{3}{|c|}{ 4. Frequency of motile sperm (\%) } \\
\hline$>50$ & 32 & 16 \\
\hline $20.1-50$ & 48 & 24 \\
\hline $5-20$ & 120 & 60 \\
\hline Total & 200 & 100 \\
\hline \multicolumn{3}{|c|}{ 5. Abnormality } \\
\hline Oligozoospermia & 70 & 35 \\
\hline Oligoasthenozoospermia & 85 & 42.5 \\
\hline Azoospermia & 34 & 17 \\
\hline Aspermia & 3 & 1.5 \\
\hline Cryptospermia & 5 & 2.5 \\
\hline Nacrospermia & 3 & 1.5 \\
\hline \multicolumn{3}{|c|}{ 6. Pus cell/HPF } \\
\hline$>10$ & 104 & 52 \\
\hline $4-10$ & 72 & 36 \\
\hline $2-3$ & 24 & 12 \\
\hline Total & 200 & 100 \\
\hline
\end{tabular}

Table-5: Motility of sperm in relation to smoking

\begin{tabular}{|c|c|c|c|c|c|c|}
\hline \multirow{2}{*}{$\begin{array}{c}\text { Sperm } \\
\text { motility }\end{array}$} & \multicolumn{4}{|c|}{ Smoker } & \multirow[t]{2}{*}{ Non-smoker } & \multirow[t]{2}{*}{ Total } \\
\hline & Mild & Moderate & Sever & Total & & \\
\hline$>50 \%$ & $17(8.5 \%)$ & $13(6.55 \%)$ & $5(2.5 \%)$ & $35(17.5 \%)$ & $42(21 \%)$ & $77(38.5 \%)$ \\
\hline $20-40 \%$ & $12(6 \%)$ & $22(11 \%)$ & $2(1 \%)$ & $36(18 \%)$ & $12(6 \%)$ & $48(24 \%)$ \\
\hline $5-19 \%$ & $3(1.5 \%)$ & $8(4 \%)$ & $12(6 \%)$ & $23(11.5 \%)$ & $14(7 \%)$ & $37(18.5 \%)$ \\
\hline$<5 \%$ & $5(2.5 \%)$ & $8(4 \%)$ & $12(6 \%)$ & $25(12.5 \%)$ & $13(6.5 \%)$ & $38(19 \%)$ \\
\hline Total & $37(18.5 \%)$ & $51(25.5 \%)$ & $31(15.5 \%)$ & $118(59 \%)$ & $82(41 \%)$ & $200(100 \%)$ \\
\hline
\end{tabular}




\section{Original Research Article}

Table-6: Count of morphologically normal sperm in relation to smoking.

\begin{tabular}{|c|c|c|c|c|c|c|}
\hline \multirow{2}{*}{$\begin{array}{c}\text { Sperm } \\
\text { morphology } \\
(\text { normal sperm) }\end{array}$} & Light & Moderate & Heavy & Total & \multirow{2}{*}{$\begin{array}{c}\text { Non- } \\
\text { smoker }\end{array}$} & Total \\
\cline { 2 - 6 } & & & & & & \\
\hline$>30 \%$ & $18(9 \%)$ & $13(6.5 \%)$ & $2(1 \%)$ & $33(16.5 \%)$ & $14(7 \%)$ & $47(23.5 \%)$ \\
\hline $20-30 \%$ & $6(3 \%)$ & $11(5.5 \%)$ & $3(1.5 \%)$ & $20(10 \%)$ & $25(12.5 \%)$ & $45(22.5 \%)$ \\
\hline $10-19 \%$ & $6(3 \%)$ & $9(4.5 \%)$ & $1(0.5 \%)$ & $16(8 \%)$ & $20(10 \%)$ & $36(18 \%)$ \\
\hline $3-9 \%$ & $3(1.5 \%)$ & $11(5.5 \%)$ & $5(2.5 \%)$ & $19(9.5 \%)$ & $12(6 \%)$ & $31(15.5 \%)$ \\
\hline$<3 \%$ & $8(4 \%)$ & $10(5 \%)$ & $12(6 \%)$ & $30(15 \%)$ & $11(5.5 \%)$ & $41(20.5 \%)$ \\
\hline Total & $\mathbf{4 1 ( 2 0 . 5 \% )}$ & $\mathbf{5 4 ( 2 7 \% )}$ & $\mathbf{2 3 ( 1 1 . 5 \% )}$ & $\mathbf{1 1 8}(\mathbf{5 9 \%})$ & $\mathbf{8 2}(\mathbf{4 1 \%})$ & $\mathbf{2 0 0}(\mathbf{1 0 0} \%)$ \\
\hline
\end{tabular}

Light Smokers: 01-20 cigarettes/day;

Moderate Smokers: 21-40 cigarettes/day; and

Heavy Smokers: 41 and more cigarettes/day.

Table 5 and 6 shows the motility and morphology of sperm in relation to smoking habit of the patients. Total 118 (59\%) patients were having smoking habit. While $82(41 \%)$ were nonsmokers. 42 out of 82 nonsmoker had good sperm motility i.e. $>50 \%$ motile sperm. Only 35 out of 118 smoker had $>50 \%$ motility while 25 had motility of $<5 \%$. Also 49 patients of smoking group had $<10 \%$ of morphologically normal sperm. While only 22 patients of nonsmoker group had $<10 \%$ of normal sperm.

Table 7 shows the sperm morphology in comparison to alcohol consumption of the patients. Within the alcoholic subgroups, teratozoospermia dominated in alcoholics $[65(32.5 \%)]$ than the nonalcoholic $[31(15.5 \%)]$ cases.

Similarly oligozoospermia was present in as high in alcoholics [55 (27.5\%)] than in nonalcoholic cases [33(16.5\%)]. All three abnormality like teratozoospermia, asthenozoospermia and oligozoospermia seen in 22 patients of alcoholic group while 7 patients of nonalcoholic group.

Table-7: alcohol consumption in relation to sperm morphology.

\begin{tabular}{|c|c|c|c|c|c|c|}
\hline \multirow{2}{*}{$\begin{array}{c}\text { Sperm } \\
\text { morphology } \\
(\text { normal sperm) }\end{array}$} & \multicolumn{4}{|c|}{ Alcoholic } & \multirow{2}{*}{$\begin{array}{c}\text { Non- } \\
\text { alcoholic }\end{array}$} & \\
\cline { 2 - 6 } & Mild & Moderate & Heavy & Total & & \\
\hline $\mathrm{N}$ & $10(5 \%)$ & $3(1.5 \%)$ & $1(0.5 \%)$ & $14(7 \%)$ & $32(16 \%)$ & $46(23 \%)$ \\
\hline $\mathrm{A}$ & $6(3 \%)$ & $2(1 \%)$ & $0(0 \%)$ & $8(4 \%)$ & $9(4.5 \%)$ & $17(8.5 \%)$ \\
\hline $\mathrm{A}+\mathrm{O}$ & $3(1.5 \%)$ & $3(1.5 \%)$ & $2(1 \%)$ & $8(4 \%)$ & $8(4 \%)$ & $16(8 \%)$ \\
\hline $\mathrm{A}+\mathrm{T}$ & $4(2 \%)$ & $6(3 \%)$ & $4(2 \%)$ & $14(7 \%)$ & $8(4 \%)$ & $22(11 \%)$ \\
\hline $\mathrm{A}+\mathrm{O}+\mathrm{T}$ & $6(3 \%)$ & $8(4 \%)$ & $8(4 \%)$ & $22(11 \%)$ & $7(3.5 \%)$ & $29(14.5 \%)$ \\
\hline $\mathrm{O}$ & $4(2 \%)$ & $6(3 \%)$ & $5(2.5 \%)$ & $15(7.5 \%)$ & $10(5 \%)$ & $25(12.5 \%)$ \\
\hline $\mathrm{O}+\mathrm{T}$ & $4(2 \%)$ & $4(2 \%)$ & $2(1 \%)$ & $10(5 \%)$ & $8(4 \%)$ & $18(9 \%)$ \\
\hline $\mathrm{T}$ & $7(3.5 \%)$ & $7(3.5 \%)$ & $5(2.5 \%)$ & $19(9.5 \%)$ & $8(4 \%)$ & $27(13.5 \%)$ \\
\hline Total & $\mathbf{4 4 ( 2 2 \% )}$ & $\mathbf{3 9}(\mathbf{1 9 . 5} \%)$ & $\mathbf{2 7}(\mathbf{1 3 . 5} \%)$ & $\mathbf{1 1 0}(\mathbf{5 5} \%)$ & $\mathbf{9 0}(\mathbf{4 5} \%)$ & $\mathbf{2 0 0}(\mathbf{1 0 0} \%)$ \\
\hline
\end{tabular}

$\mathrm{N}=$ Normozoospermia, $\mathrm{A}=$ Asthenozoospermia,

$\mathrm{O}=$ Oligozoospermia, $\mathrm{T}=$ Teratozoospermia

Mild alcohol: those consuming $40 \mathrm{~g}$ or less;

Moderate alcohol: consuming 40-80g; and

Heavy alcohol: consuming more than $80 \mathrm{~g}$ per day. 
Original Research Article

Table-8: Correlation of obesity and sperm motility

\begin{tabular}{|c|c|c|c|}
\hline & $\begin{array}{c}\text { Normal } \\
(\mathbf{B M I}=\mathbf{2 0 - 2 4} \mathbf{~ k g} / \mathbf{m} \mathbf{2})\end{array}$ & $\begin{array}{c}\text { Overweight } \\
(\mathbf{B M I}=\mathbf{2 5 - 3 0} \mathbf{~ k g} / \mathbf{m} 2)\end{array}$ & $\begin{array}{c}\text { Obese } \\
(>\mathbf{3 0} \mathbf{~ k g} / \mathbf{m} 2)\end{array}$ \\
\hline Sperm motility & & & 10 \\
\hline$>50 \%$ & 40 & 30 & 12 \\
\hline $20-40 \%$ & 15 & 20 & 13 \\
\hline $5-19 \%$ & 10 & 10 & 25 \\
\hline$<5 \%$ & 5 & 10 & $\mathbf{6 0}$ \\
\hline Total & $\mathbf{7 0}$ & $\mathbf{7 0}$ & \\
\hline
\end{tabular}

25 out of 60 obese patients had sperm motility $<5 \%$. While 10 out of 70 overweight and 5 out of 70 normal weight patients had sperm motility $<5 \%$. Good motility ( $>50 \%)$ seen in normal weight patients [40 out of $70(57.14 \%)$ ]. [Table $8]$

Table-9: Correlation between cryptorchidism and sperm count and motility

\begin{tabular}{|c|c|c|}
\hline \multicolumn{1}{|c|}{} & $\begin{array}{c}\text { Unilateral cryptorchidism } \\
(\mathbf{n = 4})\end{array}$ & $\begin{array}{c}\text { Bilateral cryptorchidism } \\
(\mathbf{n = 2})\end{array}$ \\
\hline \multicolumn{3}{|c|}{ Sperm count (million/ml) } \\
\hline Normal & 3 & 1 \\
\hline$<10$ & 1 & 0 \\
\hline$>50 \%$ & Motility & 1 \\
\hline $15-30 \%$ & 1 & 1 \\
\hline$<15 \%$ & 2 & 1 \\
\hline
\end{tabular}

Table-10: correlation between varicocele and sperm morphology abnormality.

\begin{tabular}{|c|c|}
\hline & $\begin{array}{c}\text { Patients with Varicocele } \\
(\mathrm{n}=30)\end{array}$ \\
\hline Asthenozoospermia & 14 \\
\hline Oligozoospermia & 9 \\
\hline Teratozoospermia & 7 \\
\hline
\end{tabular}

In this study 6 patients found with cryptorchidism with 4 patients had unilateral and 2 patients had bilateral cryptorchidism. Total 2 patients one from both unilateral and bilateral cryptorchidism had sperm count $<10 \mathrm{million} / \mathrm{ml}$ and motility $<15 \%$ [Table 9]. While total $30(15 \%)$ patients were found varicocele[Table 10] Among them 14 had asthenozoospermia, 9 had oligozoospermia, and 7 had teratozoospermia.

\section{Discussion}

Semen analysis is one of the most important investigations and should be done thoroughly in male partner of each infertile couple. In present study total 200 numbers of infertile patients were studied for the full semen analysis and correlation with epidemiological and other factors.

In present study, it was found that $80 \%$ of patients were from urban area. It might be because of pollution or other lifestyle related factors like stress and other factors may affect the fertility of male. The age group of presentation was 21 to 40 years with commonest age group was 25 - 30 years (mean age 28.8 years) in this study. Other study by Saxena SC [5] found the similar type of result with mean age of 30.68 years. In present study $84 \%$ patients were presented as primary infertility and $16 \%$ presented as secondary infertility. Ring \& scragg [3] found 90\% 0f men had primary Infertility and $10 \%$ cases secondary infertility. Osegbe\&amaku[6] found $64 \%$ of men had primary infertility while in 


\section{Original Research Article}

$36 \%$ cases secondary infertility was noted. Osegbe \& amaku [6] reported in their series duration of active married life varying from 1 to 28 years with mean of 5.3 years. In present study $36 \%$ had 2 to 3 years of active married life and $32 \%$ had 4 to 5 years of active married life with mean of 4.96 years. In patients with 2 years of active married life, this was reduced to $5 \%$ after 6 years of active married life. Thus shorter the duration of male related infertility, better the prognosis.

In present study, the mean of semen quantity was 1.8 c.c. Saxena [5] reported a mean of 2.0 c.c. Osegbe and Amaku [6] reported semen volume ranging from 0.4 to $10 \mathrm{ml}$, with a mean of 2.56 c.c. Mclane[7] suggested homologous insemination be performed if semen volume is $1.5 \mathrm{ml}$ or less. In this series, there were 4 patient (16\%) who had semen quantity less than or equal to $1 \mathrm{ml}$. The sperm density in present study is compared with study by McLeod and Gold et al.[8], Saxena et al. [5], and Zukerman et al. [9].

\begin{tabular}{|c|c|c|c|}
\hline Authors & Sperm density(millions/ml) & & $>20$ \\
\hline & $<10$ & $10.1-20$ & $84 \%$ \\
\hline Present study & $4 \%$ & $12 \%$ & $86 \%$ \\
\hline McLeod and Gold et al (1951) [8] & $9 \%$ & $5 \%$ & $64.9 \%$ \\
\hline Saxena et al. (1972) [5] & $33.1 \%$ & $14 \%$ & $58 \%$ \\
\hline Zukerman et al. (1977) [9] & $28 \%$ & $2 \%$ & \\
\hline
\end{tabular}

It was found that $34.2 \%$ of nonsmokers showed below 5\% sperm motility and $65.7 \%$ of smokers showed below $5 \%$ sperm motility. Among the 3 groups of smokers, sperm motility below 5\% was present in 20\% of light smokers, $32 \%$ of moderate smokers, and 48\% of heavy smokers. In similar result were obtained by Zhang et al. in 2000 [10].

The sperm motility was below $5 \%$ in $30 \%$ of non smoker while $70 \%$ of smokers. The sperm morphology was normal below $3 \%$ in $26.8 \%$ of non smokers while $73.1 \%$ of smokers. Among the 3 groups of smokers, morphology of sperm, less than $3 \%$ of normal sperm cells were present in $26.6 \%$ of light, $33.3 \%$ of moderate, and $40 \%$ of heavy smokers.

Thus the highest abnormal sperms are present in heavy smokers and it also suggests that as the amount of smoking increases, it also increases the number of abnormal sperms. This is also supported by Zukerman et al [9]. In 21\% non smoker showed below 3\% normal sperm morphology and 69\% in smoker.

$14(30.4 \%)$ patients of alcoholics showed normozoospermia, of which 10(71.4\%) were mild alcoholics and 1(7.1\%) was heavy alcoholics. 32(69.5\%) cases of non alcoholic showed normozoospermia. This study was comparable to previous study of VillaltaJ [11] showed in $15 \%$ in heavy smoker and $72 \%$ in non alcoholic cases.

In present study 70 patients (35\%) were normal weight, $70(35 \%)$ overweight and $60(30 \%)$ obese patient. $<5 \%$ Sperm motility is noted in $25(41.6 \%)$ in obese patient while only $5(7.1 \%)$ Normal weight patient. In the present study $>50 \%$ sperm motility was noted in 40(57.1\%) obese patient. Korte et al [12] concluded that men with high BMI values (>25) present with only few normal-motile sperm cells.

Pus cells $>4$ in number in semen sample are an indicative of infection in the male reproductive tract. Normally up to 1-2 pus cells/HPF are present in semen sample. 9 (36\%) patients had pus cells count ranging between 4-10 pus cells/HPF indicating moderate infection. There were 3(12\%) patients who had more than 10 pus cells/HPF indicating severe infection. Saxena [5] reported $20 \%$ cases with severe infections.

The sperm count was normal in $75 \%$ unilateral cryptorchidism patient while $50 \%$ of bilateral cryptorchidism. Nistal M et al [13] study $95 \%$ normal sperm count in unilateral and 50\% in bilateral cryptorchidism. In present study $15 \%$ cases of varicocele.

Out of them 46.6\% examined asthenozoospermia, 30\% oligospermia and 23.3 \% teratozoospermia. Ali Ali BM 2010 [14] showed $36 \%$ asthenozoospermia, $25 \%$ oligospermia and $21 \%$ teratozoospermia. 


\section{Original Research Article}

\section{Conclusion}

In conclusion smoking and alcohol decrease fertility by decreasing sperm count, motility and also by changing the morphology of sperm. Obesity also directly contributing the fertility by altering the hormonal status of patients. Presence of pus cells suggests infective etiology.

Along with the other etiological factors like smoking, obesity, varicocele and hormonal abnormality, infective etiology is also responsible for infertility.

Funding: Nil, Conflict of interest: None initiated, Permission from IRB: Yes

\section{References}

1. Bayer, SR, Alper, MM, Penzias, AS, The Boston IVF handbook of infertility: a practical guide for practitioners who care for infertile couples. 2nd ed. London: Informa healthcare; 2007. p259.

2. Manson MC. Male infertility-men talking. London: Routledge; 1993. p211.

3. Ring \& scragg, Rowe PJ, Comhaire FH, Hargreave TB, Mahmoud AM. WHO manual for the standardized investigation and diagnosis of the infertile male. UK: Cambridge University press; 2000. p91.

4. Fritz MA, Speroff L. Clinical gynecologic endocrinology and infertility. Lippincot Williams Wilkins: Philadelphia. 2012. P. 1266-1275.

5. Saxena SC. Proceedings of the all India obstetrics and gynaecological congress 1973.

6. Osegbe DN, Amaku EO.Semen features of 596 truly infertile men. Eur Urol. 1987;13(3):169-73.
7. Mclane. Parameters of male infertility. H.P. Publishing Co: New York, 1973.

8. Macleod J. The semen examination. clinical orbs and gynaec 1965;8:115.

9. Zukerman Z, Rodriguez-Rigau LJ, Smith KD, Steinberger E. Frequency distribution of sperm counts in fertile and infertile males. FertilSteril. 1977 Dec;28 (12): 1310-3.

10. Zhang JP, Meng QY, Wang Q, Zhang LJ, Mao YL, Sun ZX. Effect of smoking on semen quality of infertile men in Shandong, China. Asian J Androl. 2000 Jun;2 (2): 143-6.

11. Villalta, J., Ballesca, J.L., Nicolas, J.M., Martinez de Osaba, M.J., Antunez, E.,Pimentel, C. Testicular function in asymptomatic chronic alcoholics (relation to ethanol intake). Alcohol ClinExp Res. 1997;21:128.

12. Kort HI, Massey JB, Elsner CW, Mitchell-Leef D, Shapiro DB, Witt MA, Roudebush WE. Impact of body mass index values on sperm quantity and quality. J Androl. 2006 May-Jun;27(3):450-2. Epub 2005 Dec 8.

13. Nistal M, Paniagua R, Riestra ML, Reyes-Múgica M, Cajaiba MM. Bilateral prepubertal testicular biopsies predict significance of cryptorchidismassociated mixed testicular atrophy, and allow assessment of fertility. Am J SurgPathol. 2007 Aug;31 (8): 1269-76.

14. Al-Ali BM, Marszalek M, Shamloul R, Pummer K, Trummer H. Clinical parameters and semen analysis in 716 Austrian patients with varicocele. Urology. 2010; 75: 1069-1073.

\section{How to cite this article?}

Tandel H.K, Patel Y.K. Analysis of factors affecting the semen pathology in male infertility. Trop J Path Micro 2018;4(1):14-21.doi: 10.17511/jopm.2018.i1.03. 